\title{
Low back pain in hemodialysis patients: Risk factors and its impact on health-related quality of life
}

\author{
Bilge Kesikburun, ${ }^{1}$ Emel Ekşsioğlu, ${ }^{1}$ İbrahim Akdağ,,${ }^{2}$ Aytül Çakç ${ }^{1}$ \\ ${ }^{1}$ Department of Physical Medicine and Rehabilitation, Dışkapı Ylldırım Beyazıt Training and Research Hospital, Ankara, Turkey \\ ${ }^{2}$ Department of Nephrology, Dışkapı Ylldırım Beyazıt Training and Research Hospital, Ankara, Turkey \\ Received: November 01, 2016 Accepted: April 14, 2017 Published online: November 15, 2017
}

\begin{abstract}
Objectives: The aim of this study was to evaluate frequency and characteristics of low back pain and to identify possible risk factors of low back pain and its impact on health-related quality of life in hemodialysis patients.

Patients and methods: A total of 87 hemodialysis patients (41 males, 46 females; mean age: $53.3 \pm 15.8$ years; range, 21 to 80 years) were included in the study between January 2015 and July 2015. Medical charts and face-to-face interviews were used to collect clinical and demographic data. A comprehensive clinical evaluation of low back pain was implemented. The patients were divided into two groups: those with $(n=32)$ and without $(n=55)$ low back pain. Demographic data, quality of life, pain, and disability were compared between the groups. Pain severity was assessed using the Visual Analog Scale (VAS). Low back pain-associated disability was measured using the Oswestry Disability Index (ODI). Risk factors of low back pain were identified using multiple logistic regression analysis. The impact of low back pain on health-related quality of life was measured using the Nottingham Health Profile (NHP).

Results: Advanced age, increased body mass index, and smoking were found to be significant independent risk factors of low back pain $(\mathrm{p}=0.048 ; \mathrm{p}=0.037 ; \mathrm{p}=0.020$, respectively). Energy, pain, and physical mobility subscale scores of the NHP were also higher in the hemodialysis patients with low back pain ( $\mathrm{p}=0.008 ; \mathrm{p}<0.001 ; \mathrm{p}<0.001$, respectively). Energy, pain, sleep, and physical mobility subscale scores of the NHP showed a significant positive correlation with the ODI scores $(r=0.424, p=0.016 ; r=0.803, p<0.001 ; r=0.493, p=0.004 ; r=0.862$, $\mathrm{p}<0.001$, respectively). The etiology of low back pain was non-specific in the majority of the patients (71.9\%). There were spondylodiscitis in two patients (6.2\%), compression fractures in two patients (6.2\%), spinal stenosis in one patient (3.1\%), and discopathy in four patients (12.5\%). Conclusion: Low back pain is a common condition in hemodialysis patients. Advanced age, increased body mass index, and smoking are the main risk factors of low back pain. The presence of low back pain is also related to poor health-related quality of life in hemodialysis patients.

Keywords: Hemodialysis; low back pain; quality of life.
\end{abstract}

The pain is one of the most frequently reported conditions associated with poor health-related quality of life (HRQOL) in hemodialysis patients. The most common source of pain has been reported as musculoskeletal problems as well as neuropathic, visceral, underlying kidney disease, comorbidities, and dialysis therapy. ${ }^{[1]}$ Low back pain (LBP) is also one of the major causes of musculoskeletal pain in hemodialysis patients. ${ }^{[2]}$

As LBP is a common health problem, many individuals experience LBP at some point their lives. ${ }^{[3]}$ It mostly originates from bones, intervertebral discs, joints, muscles, ligaments, neural structures, and blood vessels. ${ }^{[4]}$ In the minority of cases, LBP is caused by a specific etiological factor, including infection, tumor, or osteoporotic fractures. ${ }^{[4]}$ In hemodialysis patients, LBP can be attributed to sedentary lifestyle, low physical performance, muscular weakness, psychological factors, altered metabolic activity of the bones and joints, and rare causes such as tumor, spinal infection, and osteoporotic fractures. ${ }^{[5]}$

Low back pain may not be paid attention sufficiently due to the occurrence of many complications in hemodialysis patients. However, it is potential source of morbidity, disability, psychosocial problems, and poor HRQOL in this patient population. In the present study,

Corresponding author: Bilge Kesikburun, MD. Dışkapı Ylldırım Beyazıt Eğitim ve Araştırma Hastanesi, Fiziksel Tıp ve Rehabilitasyon Kliniği, 06110 Dışkapı, Ankara, Turkey. e-mail: drbilgekb@gmail.com 
we aimed to evaluate the frequency and characteristics of LBP and to identify possible risk factors of LBP and its impact on HRQOL in hemodialysis patients.

\section{PATIENTS AND METHODS}

This cross-sectional study was conducted at Hemodialysis Department of Physical Medicine and Rehabilitation, Dışkapı Yıldırım Beyazıt Training and Research Hospital, between January 2015 and July 2015. The patients who had clinically stable end-stage renal disease, aged between 18 and 80 years, had ability to interview and complete the questionnaires in Turkish, and who underwent hemodialysis three times a week for over three months were eligible to be included in the study. Those who had cognitive impairment and uncontrolled systemic diseases were excluded from the study. As a result, a total of 87 patients were included in this study. All patients were divided into two groups: those with $(n=32)$ and without $(n=55)$ LBP. Demographic data, quality of life, pain severity, and disability were compared between the two groups.

A written informed consent was obtained from each patient. The study protocol was approved by the local Ethics Committee. The study was conducted in accordance with the principles of the Declaration of Helsinki.

\section{Data collection and outcome measures}

Baseline demographic and clinical laboratory data including age, sex, body mass index (BMI), education status, history of smoking, marital status, and duration of dialysis were collected from the medical charts and face-to-face interviews. Comorbidities such as diabetes mellitus, hypertension, cardiac diseases, and cerebrovascular disease were questioned. Blood tests including level of hemoglobin, creatinine, albumin, calcium, phosphate, parathyroid hormone, and alanine aminotransferase (ALT) were performed.

The HRQOL was assessed using the Nottingham Health Profile (NHP). The NHP is a questionnaire designed to measure the social and personal effects of illness. ${ }^{[6]}$ It contains 38 items divided into six dimensions: energy, pain, emotional reaction, sleep, social isolation, and physical mobility. The scores of each component are weighted to give a score from 0 (no problems) to 100 (maximum problems). The respondent answers 'Yes', if the statement adequately reflects the current status or feeling, or 'No' otherwise. The Turkish adaptation of the NHP was previously performed. ${ }^{[7]}$
The severity of depression was assessed using Beck Depression Inventory (BDI), which is a 21 item selfreport scale. Items in the scale are rated from 0 to 3 in increasing order of severity. Item scores are totaled and can range from 0 to 63 . Higher scores correlate with more severe depression. The pathologic cut-off value for the BDI score determined to be 17 in the Turkish population. The validity of reliability of the Turkish version of the scale have been established. ${ }^{[8,9]}$

\section{Evaluation of low back pain}

The patients were asked whether they had LBP at the time of the interview. The Delphi definition was used to define LBP: "Pain between the inferior margin of the $12^{\text {th }}$ rib and inferior gluteal folds that is bad enough to limit usual activities or change the daily routine for more than 1 day. This pain can be with or without pain going down into the leg. This pain does not include pain from feverish illness or menstruation." ${ }^{\text {"[10] }}$ Those who had LBP were asked about duration, severity of pain, and location including axial LBP and pain radiating from low back to the leg. Severity of pain was assessed using the Visual Analog Scale (VAS) ranging from $0 \mathrm{~mm}$ (no pain) to $10 \mathrm{~mm}$ (worst pain). The recommended cut-points are as follows: no pain (0), mild pain (0-4), moderate pain (5-7), and severe pain (8-10). ${ }^{[1]}$ Pain duration of more than three months was deemed as chronic. A comprehensive physical examination including palpation of the paravertebral muscles and spinous process, LBP movements, neurological examination of the lower extremities, and specific tests such as straight leg raise test and femoral nerve stretch test was performed. In addition to physical examination findings, imaging of the LBP including $\mathrm{X}$-ray and magnetic resonance imaging (MRI) were assessed to determine a specific etiology for LBP. Red flags of LBP including age over 50 years, bladder dysfunction, history of cancer, immune suppression, nocturnal pain, history of trauma, saddle anesthesia, and neurological deficits in the lower extremities, were questioned.

Disability related to LBP was evaluated with a disease-specific functional status questionnaire, namely the Oswestry Low Back Pain Disability Index (ODI). Each question is rated on a scale from 0 to 5 points, with a higher score indicating high disability. The ODI scores range from 0 to 50 . The Turkish validity and reliability of ODI were previously carried out. ${ }^{[12]}$

\section{Statistical analysis}

Statistical analysis was performed using the IBM-SPSS for MAC version 20.0 software 
(IBM Corp., Armonk, NY, USA). Descriptive data were expressed in mean \pm standard deviation (SD) for continuous variables and in percentage for categorical variables. The chi-square test was applied to compare the groups. The Student's t-test was used to compare the mean values of continuous variables between the patients with and without LBP. If the distribution of the continuous variables was abnormal, the Mann-Whitney test was used. Given the binary nature of the main outcome of interest (i.e., presence of LBP vs absence of LBP), univariate binary logistic regression analysis was used to yield odds ratios (ORs) and 95\% confidence intervals (CIs) to identify the variables included in the multivariate analysis. Multiple logistic regression analysis was used to investigate the risk factors of LBP. Those variables with $\mathrm{p}<0.25$ in the univariate analysis and identified individually as significant risk factors of LBP were included in the multivariate model. Low back pain status (i.e., presence of LBP vs absence of LBP) was accepted as the dependent variable in the multivariate model. Variables which were likely to affect LBP status were accepted as independent variables. The Pearson's correlation analysis was performed to analyze correlation between the ODI and
NHP subscale scores. A two-tailed p-value of $<0.05$ was considered statistically significant.

Power analysis was performed using the pain subscale of the NHP as primary outcome. The difference between the mean values of the groups was found to be 34.3. The intra-group standard deviation was found to be 31.4. The ratio of control to experimental patients was 1.71 . Based on type I error of 0.05 , the study power was calculated as 0.954 , according to the primary outcome. The PS version 3.0 program (IBM Corp., Armonk, NY, USA) was utilized. A two-tailed test was used for the analysis.

\section{RESULTS}

Of a total of 102 patients undergoing hemodialysis were screened; however, 15 of them who did not meet the eligibility criteria were excluded. Among these, five patients rejected to participate, three patients had mental retardation, two patients had impaired hearing, four patients had impaired cognition, and one patient was unable to interview and complete the questionnaires in Turkish. As a result, a total of 87 patients were included. Of these patients, 41 (47.1\%)

Table 1. Characteristics of hemodialysis patients with and without low back pain

\begin{tabular}{|c|c|c|c|c|c|c|c|c|c|}
\hline & \multicolumn{3}{|c|}{$\begin{array}{c}\text { Hemodialysis patients } \\
\text { with low back pain }(n=32)\end{array}$} & \multicolumn{3}{|c|}{$\begin{array}{c}\text { Hemodialysis patients } \\
\text { without low back pain }(n=55)\end{array}$} & \multirow[b]{2}{*}{ OR } & \multirow[b]{2}{*}{$95 \% \mathrm{CI}$} & \multirow[b]{2}{*}{$p$} \\
\hline & $\mathrm{n}$ & $\%$ & Mean \pm SD & $\mathrm{n}$ & $\%$ & Mean \pm SD & & & \\
\hline Age (year) & & & $58.0 \pm 14.5$ & & & $50.7 \pm 16.0$ & 1.03 & $1.00-1.06$ & 0.041 \\
\hline Sex & & & & & & & & & 0.631 \\
\hline Female & 18 & 56.3 & & 28 & 50.9 & & 1.24 & $0.51-2.97$ & \\
\hline Male & 14 & 43.7 & & 27 & 49.1 & & & & \\
\hline Body mass index $\left(\mathrm{kg} / \mathrm{m}^{2}\right)^{*}$ & & & $25.7 \pm 4.3$ & & & $23.9 \pm 3.4$ & 1.13 & $1.00-1.28$ & 0.035 \\
\hline Marital status & & & & & & & & & 0.273 \\
\hline Married & 21 & 65.6 & & 29 & 52.7 & & 1.71 & $0.69-4.21$ & \\
\hline Not married & 11 & 34.4 & & 26 & 47.3 & & & & \\
\hline Education period (year) ${ }^{*}$ & & & $3.7 \pm 3.9$ & & & $4.5 \pm 3.6$ & 0.94 & $0.83-1.06$ & 0.352 \\
\hline Duration of hemodialysis (year) ${ }^{*}$ & & & $6.4 \pm 6.2$ & & & $7.4 \pm 6.4$ & 0.97 & $0.90-1.04$ & 0.462 \\
\hline Smoking & 7 & 21.9 & & 7 & 12.7 & & 1.92 & $0.60-6.08$ & 0.248 \\
\hline \multicolumn{10}{|l|}{ Comorbidities } \\
\hline Arterial hypertension & 21 & 65.6 & & 30 & 54.5 & & 1.59 & $0.64-3.92$ & 0.313 \\
\hline Diabetes mellitus & 9 & 28.1 & & 14 & 25.4 & & 1.14 & $0.43-3.05$ & 0.785 \\
\hline Cardiac disease & 7 & 21.8 & & 10 & 18.1 & & 1.26 & $0.42-3.72$ & 0.676 \\
\hline Cerebrovascular disease & 1 & 3.1 & & 3 & 5.4 & & 0.55 & $0.05-5.61$ & 0.621 \\
\hline Beck depression inventory ${ }^{\star}$ & & & $14.9 \pm 2.6$ & & & $11.7 \pm 1.5$ & 1.03 & $0.99-1.06$ & 0.066 \\
\hline \multicolumn{10}{|l|}{ Laboratory tests ${ }^{*}$} \\
\hline Hemoglobin (g/dL) & & & $10.8 \pm 1.4$ & & & $10.8 \pm 1.4$ & 1.02 & $0.75-1.38$ & 0.893 \\
\hline Creatinine $(\mathrm{mg} / \mathrm{dL})$ & & & $7.6 \pm 2.0$ & & & $7.3 \pm 2.1$ & 0.66 & $0.69-1.06$ & 0.374 \\
\hline Albumin $(\mathrm{mg} / \mathrm{dL})$ & & & $3.6 \pm 0.6$ & & & $3.8 \pm 0.3$ & 0.43 & $0.14-1.26$ & 0.125 \\
\hline Calcium (mg/dL) & & & $8.5 \pm 0.6$ & & & $8.7 \pm 0.9$ & 0.78 & $0.45-1.34$ & 0.380 \\
\hline Phosphate (mg/dL) & & & $5.4 \pm 1.6$ & & & $5.1 \pm 1.4$ & 1.10 & $0.82-1.47$ & 0.491 \\
\hline Parathyroid hormone (pg/mL) & & & $406.3 \pm 459.7$ & & & $564.7 \pm 543.5$ & 0.99 & $0.99-1.00$ & 0.175 \\
\hline Alanine aminotransferase (U/L) & & & $15.1 \pm 11.4$ & & & $13.1 \pm 6.9$ & 1.02 & $0.97-1.07$ & 0.337 \\
\hline
\end{tabular}

SD: Standard deviation; OR: Odds ratio; CI: Confidence interval. 
Table 2. Clinical characteristics of low back pain

\begin{tabular}{|c|c|c|}
\hline & \multicolumn{2}{|c|}{$\begin{array}{c}\text { Hemodialysis patients } \\
\text { with low back pain }(n=32)\end{array}$} \\
\hline & $\mathrm{n}$ & $\%$ \\
\hline \multicolumn{3}{|l|}{ Location } \\
\hline Axial low back pain & 9 & 28.1 \\
\hline Low back pain radiating to the legs & 23 & 71.9 \\
\hline \multicolumn{3}{|l|}{ Duration } \\
\hline Acute (<3 month) & 11 & 34.4 \\
\hline Chronic ( $\geq 3$ month) & 21 & 65.6 \\
\hline \multicolumn{3}{|l|}{ Intensity } \\
\hline Mild (VAS 0-4) & 16 & 50.0 \\
\hline Moderate (VAS 5-7) & 12 & 37.5 \\
\hline Severe (VAS 8-10) & 4 & 12.5 \\
\hline \multicolumn{3}{|l|}{ Etiology } \\
\hline Spondylodiscitis & 2 & 6.2 \\
\hline Compression fracture & 2 & 6.2 \\
\hline Spinal stenosis & 1 & 3.1 \\
\hline Discopathy & 4 & 12.5 \\
\hline Non-specific & 23 & 71.9 \\
\hline
\end{tabular}

VAS: Visual Analog Scale.

were males and 46 (52.9\%) were females. The mean age was $53.3 \pm 15.8$ (range, 21 to 80 ) years. The mean duration of hemodialysis was $7.0 \pm 6.3$ years. Demographic and clinical characteristics of the patients are presented in Table 1.

A total of 32 patients (36.8\%) had LBP at the time of the interview. There were nine patients $(28.1 \%)$ with axial LBP and 23 patients (71.9\%) with LBP radiating
Table 3. Multivariate analysis of risk factors of low back pain

\begin{tabular}{lccc}
\hline & OR & $95 \%$ CI & $p$ \\
\hline Age (year) & 1.02 & $1.00-1.06$ & 0.048 \\
Body mass index $\left(\mathrm{kg} / \mathrm{m}^{2}\right)$ & 1.24 & $1.01-1.41$ & 0.037 \\
Smoking & 7.11 & $1.60-6.08$ & 0.020 \\
\hline
\end{tabular}

OR: Odds ratio; CI: Confidence interval.

to the leg. Severity of LBP was mild in 16 patients $(50.0 \%)$, moderate in 12 patients $(37.5 \%)$, and severe in four patients (12.5\%). Eleven patients (34.4\%) had acute LBP and 21 patients (65.6\%) had chronic LBP. The etiology of low back pain was non-specific in the majority of the patients (71.9\%). There were spondylodiscitis in two patients (6.2\%), compression fractures in two patients $(6.2 \%)$, spinal stenosis in one patient (3.1\%), and discopathy in four patients (12.5\%). Clinical characteristics of LBP are shown in Table 2.

According to the univariate binary logistic regression analysis in patients with and without LBP as shown in Table 1, advanced age and increased BMI were significantly related to an increased likelihood of LBP ( $p=0.041 ; p=0.035$, respectively). Age, BMI, and smoking which were identified as the risk factors of LBP in the univariate regression were included in the multivariate analysis. The ORs and 95\% CIs for each variable are presented in Table 3. Advanced age, increased BMI, and smoking were found to be significant independent risk factors of LBP in

Table 4. Comparison of Nottingham Health Profile subscale scores ${ }^{\star}$ between hemodialysis patients with and without low back pain

\begin{tabular}{lccc}
\hline & $\begin{array}{c}\text { Hemodialysis patients } \\
\text { with low back pain }(\mathrm{n}=32)\end{array}$ & & $\begin{array}{c}\text { Hemodialysis patients } \\
\text { without low back pain }(\mathrm{n}=55)\end{array}$ \\
\cline { 2 - 2 } & $84.3 \pm 29.3$ & & Mean \pm SD \\
Energy & $49.9 \pm 36.8$ & $58.7 \pm 47.1$ & 0.002 \\
Pain & $36.0 \pm 30.1$ & $15.6 \pm 26.1$ & $<0.001$ \\
Emotional reaction & $50.0 \pm 41.2$ & $35.1 \pm 30.8$ & 0.888 \\
Sleep & $19.9 \pm 30.0$ & $40.3 \pm 42.2$ & 0.304 \\
Social isolation & $49.2 \pm 37.0$ & $17.4 \pm 30.0$ & 0.713 \\
Physical mobility & & $19.3 \pm 29.4$ & $<0.001$ \\
\hline
\end{tabular}

SD: Standard deviation.

Table 5. Correlation between Oswetry Disability Index and Nottingham Health Profile subscale scores

\begin{tabular}{lcc}
\hline & \multicolumn{2}{c}{ Oswetry Disability Index } \\
\cline { 2 - 3 } & $\mathrm{r}$ & $\mathrm{p}$ \\
\hline Energy & 0.424 & 0.016 \\
Pain & 0.803 & $<0.001$ \\
Emotional reaction & 0.258 & 0.154 \\
Sleep & 0.493 & 0.004 \\
Social isolation & 0.056 & 0.760 \\
Physical mobility & 0.862 & $<0.001$ \\
\hline
\end{tabular}


hemodialysis patients $(\mathrm{p}=0.048 ; \mathrm{p}=0.037 ; \mathrm{p}=0.020$, respectively).

Energy, pain, and physical mobility subscale scores of the NHP were higher in the hemodialysis patients with LBP than those without LBP $(\mathrm{p}=0.008 ; \mathrm{p}<0.001$; $\mathrm{p}<0.001$, respectively) (Table 4 ). In addition, energy, pain, sleep, and physical mobility subscale scores of the NHP showed a significant positive correlation with the ODI scores $(\mathrm{r}=0.424, \mathrm{p}=0.016 ; \mathrm{r}=0.803, \mathrm{p}<0.001$; $\mathrm{r}=0.493, \mathrm{p}=0.004 ; \mathrm{r}=0.862, \mathrm{p}<0.001$, respectively) (Table 5).

\section{DISCUSSION}

In the present study, we investigated the frequency and characteristics of LBP and identified possible risk factors of LBP and its impact on HRQOL in hemodialysis patients. Our study results showed that advanced age, increased BMI, and smoking were the main risk factors of LBP in hemodialysis patients. In addition, we found that hemodialysis patients with LBP had worse HRQOL scores, compared to those without LBP. Finally, we found a significant correlation between LBP-associated disability and HRQOL domains.

In the literature, there is a limited number of studies on LBP in hemodialysis patients. In the study of Cristofolini et al. ${ }^{[5]}$ LBP was present in $36 \%$ of the patients and was associated with muscle weakness, balance disorders, and comorbidities. Similarly, in our study, $36.8 \%$ of the hemodialysis patients had LBP. In the general population, estimates of the point prevalence of LBP are about $18.1 \%$; therefore, we can conclude that LBP is seen more frequently in hemodialysis patients, compared to the general population.

A total of 5 to $15 \%$ of LBP can be explained by specific causes, such as infection, tumor, or osteoporotic fractures in the general population. ${ }^{[4]}$ However, in 85 to $95 \%$ of the LBP cases, the etiology is unclear. ${ }^{[4,13,14]}$ In the present study, spondylodiscitis, compression fractures, spinal stenosis, and discopathy were the main causes of LBP in $30 \%$ of our study population. However, non-specific LBP was the most frequent condition. Two patients with spondylodiscitis were detected in this study. Advanced age hemodialysis patients may be rarely prone to spondylodiscitis as a result of bacteremia. ${ }^{[15]}$ Spondylodiscitis is important due to related morbidity and mortality; therefore early diagnosis and effective therapy are life saving. ${ }^{[16]}$
In the present study, LBP was found to be associated with advanced age, increased BMI, and smoking. Epidemiological studies investigating risk factors of LBP in the general population also showed that age and increased BMI were related to increased prevalence of LBP. ${ }^{[17-19]}$ In addition, a meta-analysis demonstrated that both current and former smokers had a higher prevalence and incidence of LBP than never smokers. ${ }^{[20]}$ Nonetheless, risk factors of LBP in hemodialysis patients seem similar to those in the general population.

Furthermore, previous studies showed that the HRQOL scores were worse in hemodialysis patients. ${ }^{[21-23]}$ Body pain was found one of the most important qualitative parameters for the evaluation of the HRQOL in hemodialysis patients. ${ }^{[24]}$ To the best of our knowledge, this is the first study to specifically investigate the impact of LBP on the HRQOL in hemodialysis patients. In our study, we also found that the hemodialysis patients with LBP had significantly worse scores in the NHP subscales of energy, pain, and physical activity compared to those without LBP. Low back pain may have more adverse consequences in hemodialysis patients. Further studies may address into the additional cost of care for hemodialysis patients with LBP.

The major limitation of the study is the lack of a prospective, controlled study design. The crosssectional design did not allow the causality of the associations to be examined. In addition, the HRQOL was measured using the NHP. As a generic measure, the NHP may not be adequately sensitive as diseasespecific tools to identify the differences between hemodialysis groups.

In conclusion, our study results showed that LBP was a frequent condition in hemodialysis patients. Risk factors of LBP were similar to the general population, and LBP was associated with poor HRQOL scores in hemodialysis patients. Based on these findings, with increasing number of hemodialysis survivors, the efforts should aim to improve the HRQOL in hemodialysis patients with LBP.

\section{Declaration of conflicting interests}

The authors declared no conflicts of interest with respect to the authorship and/or publication of this article.

\section{Funding}

The authors received no financial support for the research and/or authorship of this article. 


\section{REFERENCES}

1. Gamondi C, Galli N, Schönholzer C, Marone C, Zwahlen $\mathrm{H}$, Gabutti L, et al. Frequency and severity of pain and symptom distress among patients with chronic kidney disease receiving dialysis. Swiss Med Wkly 2013;143:w13750.

2. Santoro D, Satta E, Messina S, Costantino G, Savica V, Bellinghieri G. Pain in end-stage renal disease: a frequent and neglected clinical problem. Clin Nephrol 2013;79:2-11.

3. Hoy D, Brooks P, Blyth F, Buchbinder R. The Epidemiology of low back pain. Best Pract Res Clin Rheumatol 2010;24:769-81.

4. Deyo RA, Weinstein JN. Low back pain. N Engl J Med 2001;344:363-70.

5. Cristofolini T, Draibe S, Sesso R. Evaluation of factors associated with chronic low back pain in hemodialysis patients. Nephron Clin Pract 2008;108:249-55.

6. Hunt SM, McKenna SP, McEwen J, Williams J, Papp E. The Nottingham Health Profile: subjective health status and medical consultations. Soc Sci Med A 1981;15:221-9.

7. Kücükdeveci AA, McKenna SP, Kutlay S, Gürsel Y, Whalley D, Arasil T. The development and psychometric assessment of the Turkish version of the Nottingham Health Profile. Int J Rehabil Res 2000;23:31-8.

8. Hisli N, Beck Depresyon Envanteri'nin geçerliliği üzerine bir çalışma. Psikoloji Dergisi 1988;6:118-26.

9. Hisli N. Beck Depresyon Envanteri'nin üniversite öğrencileri için geçerliği, güvenirliği. Psikoloji Dergisi 1989;7:3-13.

10. Dionne CE, Dunn KM, Croft PR, Nachemson AL, Buchbinder R, Walker BF, et al. A consensus approach toward the standardization of back pain definitions for use in prevalence studies. Spine (Phila Pa 1976) 2008;33:95-103.

11. Collins SL, Moore RA, McQuay HJ. The visual analogue pain intensity scale: what is moderate pain in millimetres? Pain 1997;72:95-7.

12. Yakut E, Düger T, Oksüz C, Yörükan S, Ureten K, Turan $\mathrm{D}$, et al. Validation of the Turkish version of the Oswestry Disability Index for patients with low back pain. Spine (Phila Pa 1976) 2004;29:581-5.

13. Ehrlich GE. Low back pain. Bull World Health Organ 2003;81:671-6.
14. Hollingworth W, Todd CJ, King H, Males T, Dixon AK, Karia KR, et al. Primary care referrals for lumbar spine radiography: diagnostic yield and clinical guidelines. $\mathrm{Br} \mathrm{J}$ Gen Pract 2002;52:475-80.

15. Cervan AM, Colmenero Jde D, Del Arco A, Villanueva F, Guerado E. Spondylodiscitis in patients under haemodyalisis. Int Orthop 2012;36:421-6.

16. Kaya S, Ercan S, Kaya S, Aktas U, Kamasak K, Ozalp H, et al. Spondylodiscitis: evaluation of patients in a tertiary hospital. J Infect Dev Ctries 2014;8:1272-6.

17. Webb R, Brammah $\mathrm{T}$, Lunt $\mathrm{M}$, Urwin $\mathrm{M}$, Allison $\mathrm{T}$, Symmons D. Prevalence and predictors of intense, chronic, and disabling neck and back pain in the UK general population. Spine (Phila Pa 1976) 2003;28:1195-202.

18. Kopec JA, Sayre EC, Esdaile JM. Predictors of back pain in a general population cohort. Spine (Phila $\mathrm{Pa}$ 1976) 2004;29:70-7.

19. Waxman R, Tennant A, Helliwell P. A prospective follow-up study of low back pain in the community. Spine (Phila $\mathrm{Pa}$ 1976) 2000;25:2085-90.

20. Shiri R, Karppinen J, Leino-Arjas P, Solovieva S, ViikariJuntura E. The association between smoking and low back pain: a meta-analysis. Am J Med 2010;123:87. e7-35.

21. Diaz-Buxo JA, Lowrie EG, Lew NL, Zhang H, Lazarus JM. Quality-of-life evaluation using Short Form 36: comparison in hemodialysis and peritoneal dialysis patients. Am J Kidney Dis 2000;35:293-300.

22. Merkus MP, Jager KJ, Dekker FW, De Haan RJ, Boeschoten EW, Krediet RT. Quality of life over time in dialysis: the Netherlands Cooperative Study on the Adequacy of Dialysis. NECOSAD Study Group. Kidney Int 1999;56:720-8.

23. Zyga S, Alikari V, Sachlas A, Stathoulis J, Aroni A, Theofilou $\mathrm{P}$, et al. Management of Pain and Quality of Life in Patients with Chronic Kidney Disease Undergoing Hemodialysis. Pain Manag Nurs 2015;16:712-20.

24. Hsu HJ, Yen CH, Hsu KH, Wu IW, Lee CC, Hung MJ, et al. Factors associated with chronic musculoskeletal pain in patients with chronic kidney disease. BMC Nephrol 2014;15:6. 